\title{
Travel Package Recommendation System based on Package Locations and Rating
}

\author{
Jadhav Dipali \\ $\mathrm{BE}($ Computer)
}

\author{
Sanap Pragati \\ BE(Computer)
}

\author{
Undre Pratik \\ $\mathrm{BE}($ Computer)
}

\author{
Mahajan Yogeshwari \\ $\mathrm{BE}($ Computer)
}

\begin{abstract}
Throughout the decades, travelling has encountered constant development and extending expansion to wind up noticeably one of the quickest developing monetary segments on the planet. Among the current travelling applications, just a modest bunch encourage the capacity to design a visit which is totally in light of client inclinations, while offering a top to bottom take a gander at the coveted goal. Hence, this examination concentrates on coordinating semantic innovations, cooperative sifting into the area of travelling and give client arranged visit designs with superlative client fulfilment. Visit arranging and the method for investigating wanted courses, real stops or attractions en route by means of virtual reality 360 view understanding. Moreover, business associations can utilize the electronic dashboard to keep up their administrations, offers, bundles, spending report and acquire business diagnostic based changes.
\end{abstract}

\section{General Terms}

Enhanced travel package recommendation system, Interest ratio, Personalized, User group, Watermarking, Original audio signal, Original image.

\section{Keywords}

Personalized Tour Plans; Semantic-Matching; 360 degree view; Tour Suggestions

\section{INTRODUCTION}

It is a web based application for tourism management with the help of different algorithms for enhancing the speed of searching the results. This project will help tourists for better experience of travelling with less efforts to find out the places. This project using the algorithm for fastest route finding with optimal distance, it is also using the recommendation system for better options of travelling, it will create the most suitable packages through the rating system.

. Travelling is an immensely developing field of concentrate over the globe. In their framework contains principally 11 modules i.e. administrator login, add packages, add special offers, user login, apply packages, get payment, weather report, select guide, guide login, view user, budget report details and many more. Current web administrations are improved with location aware highlights, giving the client better utilize encounter 360 degree view of the particular location. So as to help the client who is more up to date to the city at the travelling time and gets present area, delineate, between two urban areas, climate report, see 360 degree view and criticism.

\section{LITERATURE SURVEY}

It tends to the unpredictable choice and visiting issue and proposes a "channel to start with, visit second" structure for producing customized visit proposals for visitors in view of data from web-based social networking and other on-line information sources. Computational investigations on benchmark datasets demonstrate that the proposed visiting calculation is extremely focused. Moreover, the proposed structure has been assessed on information gathered from Foursquare.[1]Users are equipped for getting a genuine inclination utilizing VR. Client now invest his quality time without squandering their vitality in finding appropriate aides. Traveller will have the chance of getting regular and conduct construct proposals depending in light of their inclinations.[2]This work talks about probably the most pertinent frameworks on the field and exhibits PSiS Portable, which is a versatile proposal and arranging application intended to help a vacation-er amid his get-away. It gives proposals about purposes important to visit in light of traveller inclinations and on client and sight setting. Likewise, it proposes a visit arranging which can be progressively adjusted in light of current client and sight setting. [3]Discoveries shed light on the distinctions as far as the predecessors in this unique circumstance. While the investigation exhibits the hypothetical legitimacy and the exact pertinence of the Cap model to the setting of CGM use for travel arranging, it goes further to check the critical parts of unmistakable components like voyagers' impression of closeness of premium, dependability and pleasure. [4]The proposes TRIPBUILDER, an unsupervised structure for arranging customized touring visits in urban communities. Thus it gather ordered Purposes of Interests (PoIs) from Wikipedia and collections of geo-referenced photographs from Flickr. By considering the photographs as follows uncovering the practices of voyagers amid their touring visits, it remove from photograph collections spatio-worldly data about the agendas made by visitors, and it coordinate these schedules to the Purposes of Intrigue (PoIs) of the city. The assignment of prescribing a customized touring visit is demonstrated as a case of the Summed up Most extreme Scope (GMC) issue, where a measure of individual enthusiasm for the client given her inclinations and going by time-spending plan is amplified. [5]It displays the improvement of the Traveller Guide, an area based vacation-er control application for the open air condition. Its concentrate for this venture is on programming support for area based applications; it is occupied with the area as well as different components of the client's 
specific circumstance. For example, structures in view, attractions and gear close by, open phones and toilets. In this paper it will depict the Visitor Guide framework and examine the procedures engaged with the improvement of this application. All the more particularly, this paper will take a gander at the plan and ease of use issues. [6]Demonstrate a strategy to group goal utilizing click streams and machine learning calculations. Current personalization and suggestion systems don't give careful consideration to different shopper aims. The scientific classification of web based shopping expectation and the strategy to anticipate aim progressively are yet to be produced. In view of unsupervised and administered learning systems, this paper proposes an expectation forecast model to satisfy the exploration hole. Exact outcomes recommend that the proposed demonstrate can characterize aims correctly. [7] Arranging customized visit agendas is a perplexing and testing errand for the two people and PCs. Doing it physically is tedious; moving toward it as an advancement issue is computationally NP hard. We show Aurigo, a visit arranging framework joining a suggestion calculation with intelligent perception to make customized schedules. This half and half approach empowers Aurigo to consider both quantitative and subjective inclinations of the client. Thus it led an inside subject examination with 10 members, which showed that Aurigo helped them discover purposes of intrigue rapidly. [8] It will proposes outline and advancement of a vacation-er data framework. Its fundamental objective is to give voyagers going to Sri Lanka with an excursion design, which is customized, a la mode as data about convenience, purposes of intrigue and transportation. The expectation of this framework is to produce a grounded hypothesis about the degree to which semantic advancements can aid the creation and mix of a reliable and client situated on-line traveller data framework. [9]Algorithm Engineering is a considerable measure of fun since calculations don't leave form: one never knows when a blast from the past however good may prove to be useful. A valid example: Yesterday, Google declared Google Treks, another application to help you in your goes by helping you make your own "ideal day" in a city. Shockingly, somewhere inside Google Treks, there is a calculation that was designed 280 years back. [10]"Google Maps APIs" is going to help us the to find out the optimal path finding.[11]

\section{IMPLEMENTATION}

In this paper aim to build a prototype system which is shown in Figure, recommends personalized travel packages by taking user input and recommends packages to the user using GUI. System contains following working of a system.

As shown in figure(1), Admin, User and Guide are the main modules are there: The Admin has a authority to do any changes in the system. [eg. Admin can add, delete the location in the system]. The user need to register first in the system and after login user can search the location and give the feedback to the proposed system. Admin parse that feedback from the user and evaluate the rate of interest according to the feedback of user. The guide also need to register in the system

\section{MATHEMATICAL MODEL:}

Location based social networking provide people with an interface to share their locations and write reviews about interesting places of attraction. The shared locations form the crowd sourced digital footprints, in which each user has many connections to many locations, indicating user preference to locations. In this paper, we propose an approach for personalized travel package recommenda-

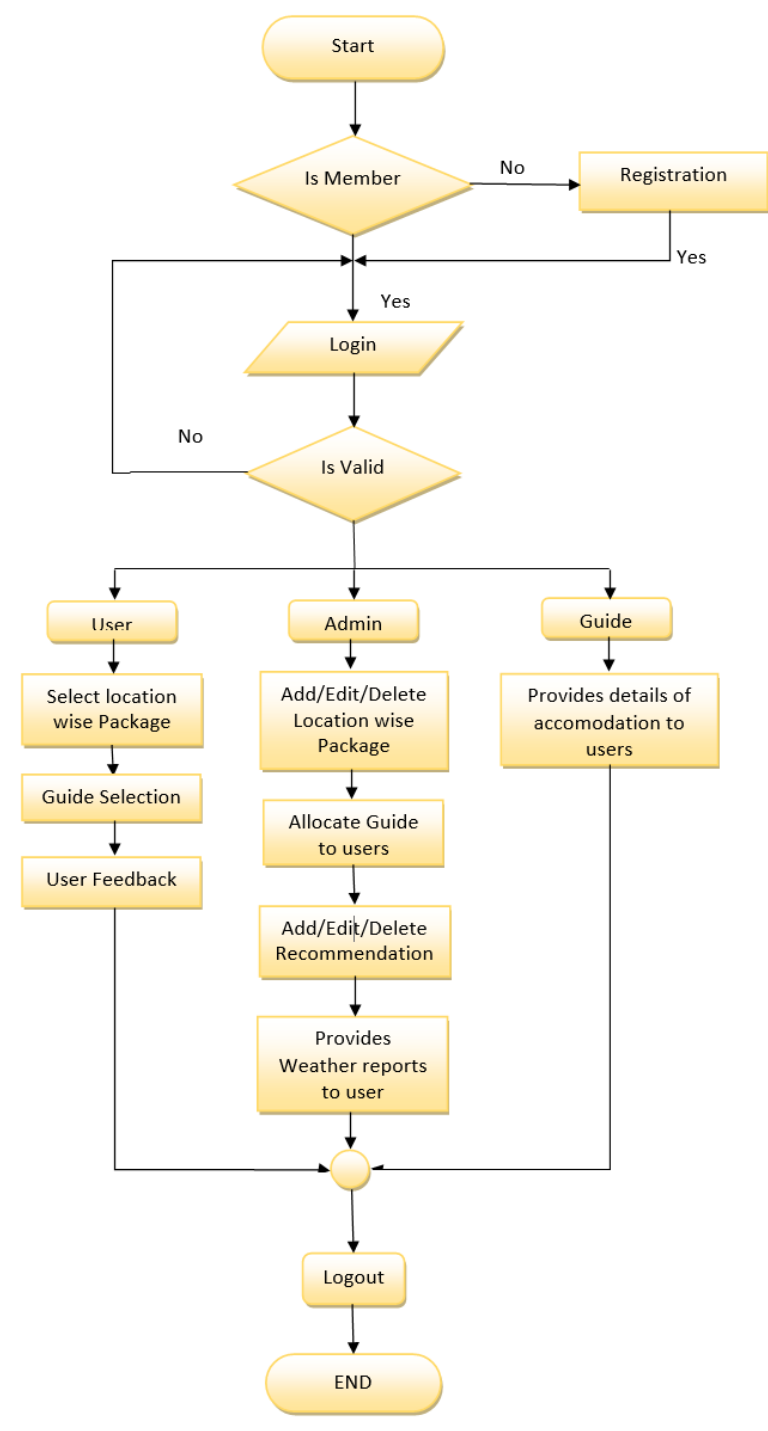

Fig. 1. Flow Diagram

tion to help users make travel plans.

System S = U, L, Q, R, SR, F

Input $=\mathrm{U}, \mathrm{L}, \mathrm{F}, \mathrm{Q}$

Output $=\mathrm{R}, \mathrm{SR}$

Where,

U Set of users

L Set of locations

Q Set of User Search Queries

F Set of User Feedbacks

R-Set of Recommendations

SR Search Results

Consider a set $\mathrm{L}$ consisting of various locations added by admin,

$$
L=L_{1}, l_{2}, L_{3} \ldots L_{n}
$$


Consider a set $\mathrm{U}$, which is a set of users registering with our system.

$$
U=U_{1}, U_{2}, U_{3} \ldots U_{n}
$$

Consider a set $\mathrm{Q}$, that is a set of queries searched by user represented as follows

$$
Q=Q_{1}, Q_{2}, Q_{3} \ldots Q_{n}
$$

The relation between User Set and query set can be represented as follows, which is one to many relationships.

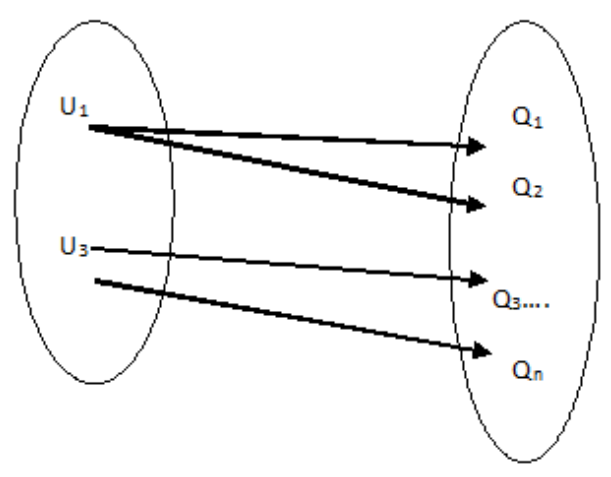

Fig. 2. Mathematical Model

The feedback set $\mathrm{F}$ can be represented as follows

$$
F=F_{1}, F_{2}, F_{3} \ldots F_{n}
$$

On basis of this interests I and the feedback $\mathrm{F}$ we can recommend the different packages to the users $\mathrm{R}$-getRecommendations (I, F) Where R- Recommendation packages which is a result of user interests and $\mathrm{F}$ is a feedbacks.

\section{ACKNOWLEDGEMENT}

We would like to take this opportunity to thanks Asst. Prof. S. S. Deshmukh for giving us all the help and guidance we needed. We are really grateful for her kind support. Her valuable suggestions were very helpful. We are also grateful towards Prof. S. R. Todmal, for his indispensable support and suggestions for time to time.

\section{CONCLUSION}

The developing system will become user friendly. User will get recommendations on location based. User will give live Feedback and rating to enhanced the package recommendation for others. The most innovative part is, the users can of getting a real view of the planned destination before they visiting the place, via 360 degree view. Users can also get the short routes suggested by use of the application along with the major stops which they can visit or attractions in the form of a virtual tour. This will help travellers to the decide choice of what they really want to see rather than taking them into what the application wants them to see and wasting their time on experiments. It will help user to select a guide for his comfort language with their mutual understanding. So, traveller can not waste there time to find the guide. User will get notification of predicted weather before actual tour.

\section{REFERENCES}

[1] S. Kotiloglu, T. Lappas, K. Pelechrinis, P.P. Repoussis, Personalized multi-period tour Recommendations ,ELSEVIER(2017).

[2] D. I. De Silva1, I. U. Kaluthanthri2 , K. S. Sudaraka3, U. P. D. Karunarathna4, J. M. T. I. Jayalath5 Scylax Preference based Personalized Tour Planner with Virtual Reality ,IEEE-2016.

[3] Anacleto , R. Figueiredo, L., Almeida, A., \& Novais, P. (2014). Mobile application to provide personalized sightseeing tours. Journal of Network and Computer Applications , 41, 56e64.

[4] Ayeh, J. K., Au, N., \& Law, R. (2013). Predicting the intention to use consumer generated media for travel planning . Tourism Management, 35, 132e143.

[5] Brilhante, I. R., Macedo, J. A., Nardini, F. M., Perego, R., \& Renso, C. (2015). On planning sightseeing tours with TripBuilder . Information Processing \& Management, 51(2), 1e15.

[6] T. Simcock, S. P. Hillenbrand and B. H. Thomas, Developing a Location Based Tourist Guide Application vol. 05, p. 7, 2003. J. Clerk Maxwell, A Treatise on Electricity and Magnetism, 3rd ed., vol. 2. Oxford: Clarendon, 1892, pp.68-73.

[7] Fanjuan Shi,IAE , Chirine Ghedira Intention-based Online Consumer Classification for Recommendation and Personalization ,IEEE(2016)

[8] A. Yahi, A. Chassang, L. Raynaud, H. Duthil and D. H. Chau, Aurigo: An Interactive Tour Planner for Personalized Itineraries, p. 11, 2015.

[9] L. Rajapaksha, L. Jayasena, P. Samarakoon and G. Wijerathna, "Web Based Intelligent Tour Planner and Advisor ", Undergraduates, Sri Lanka Institute of Information Technology, 2015.

[10] Arsintescu, B., Gollapudi, S., Kollias, K., Sarlos, T., Tomkins, A. The 280 year old algorithm inside Google trips [Blog post]. Retrieved from. 